\title{
Reactivacion de la Industria Argentina, Concentración, Extranjerización y Crecientes Desequilibrios Comerciales con Brasil
}

\author{
Daniel Aspiazu \\ Martín Schorr ${ }^{(*)}$
}

\begin{abstract}
Resumen: El artículo identifica algunos de los principales rasgos que caracterizan la reactivación de la economía y, en especial, de la industria argentina en la posconvertibilidad, a partir del quiebre del régimen de conversión fija con el dólar estadounidense. Se aborda el estudio de los sesgos estructurales que revela esa importante recuperación fabril en su relación con los que caracterizaron su desempeño durante los años noventa (patrón productivo, concentración económica y extranjerización) y las modalidades de inserción a escala mundial. Al respecto, se presta particular atención a sus impactos en términos del intercambio comercial manufacturero, en especial con el Brasil.
\end{abstract}

Palabras clave: Industria, Argentina, Concentración, Extranjerización, Desequilibrios Comerciales, Brasil.

\begin{abstract}
This paper identifies some of the main features that characterize the economic recovery, specially the "postconvertibility" Argentinean industry, from the break down of the fixed conversion regime with the American dollar. This article approaches the structural biases that reveals this significant industrial recovery in its relation with those who characterized its performance during the nineties (pattern of production, economic concentration and denationalization) and the particularities of insertion on a worldwide scale. In connection with this, particular attention is paid to its impacts in terms of manufacturing trade, particularly with Brazil.
\end{abstract}

Keywords: Industry, Argentina, Concentration, Denationalization, Commercial Imbalances, Brazil.

(*) Investigadores del CONICET y la FLACSO (Sede Académica Argentina). Este trabajo se realizó en el marco del Proyecto PIP 03153: "Desempeño y transformaciones de la cúpula empresaria argentina y la cúpula industrial entre 1991 y 2008. Rupturas y continuidades entre la convertibilidad y la posconvertibilidad”, con patrocinio del CONICET. Y se terminó de redactar el: 10.1.2010. Se agradecen los aportes del evaluador anónimo del artículo y se lo exime de cualquier responsabilidad en cuanto a los errores y las omisiones que pudieran existir. E-mail: danazpi@gmail.com e schorr_martin@yahoo.com.ar. Aceito em: 13.1.2010 e aceito em 22/03/10. 


\section{INTRODUCCIÓN}

A los efectos de encuadrar los análisis que se realizan en este trabajo, caben algunas consideraciones previas que invitan a la reflexión:

- Entre 2002 y 2008, el Producto Interno Bruto - PIB de la Argentina creció a una tasa media anual del 8,5\%, mientras que el industrial lo hizo a un ritmo aún superior (9,4\% anual acumulativo); más que duplicando los registros correspondientes a Brasil (4,1\% y 3,6\% anual, respectivamente). En la década previa, la economía y la industria argentinas acumularon una contracción media anual del o, 1\% y 1,9\%, respectivamente, al tiempo que la economía brasilera creció a un promedio anual del 2,7\% y su sector fabril al $1,5 \%$ anual acumulativo ${ }^{(1)}$.

- Por su parte, siempre entre 2002 y 2008, las exportaciones argentinas a Brasil (valuadas en dólares corrientes) se incrementaron a una tasa media del 18,7\% por año, mientras que las importaciones hicieron lo propio pero a un 39,9\% anual acumulativo; como resultado de lo cual se pasó de un superávit de 2,5 miles de millones de dólares a un déficit de 4,3 miles de millones. Ello, nuevamente contrasta con los respectivos desempeños durante la década previa (1993-2002): las exportaciones argentinas al Brasil cayeron a un ritmo medio del 7,1\% y las importaciones del país vecino lo hicieron en un $3,3 \%$ anual $^{(2)}$.

- De solo considerar el intercambio comercial de productos industriales, los resultados no difieren mayormente: al cabo del período 2002-2008, las ventas argentinas a Brasil crecieron a un ritmo medio anual del 18,9\%, al tiempo que las importaciones fabriles aumentaron a una tasa promedio del 38,4\% por año. Así, el superávit de 0,9 miles de millones de dólares de 2002 revirtió en un déficit comercial superior a 8,1 miles de millones de dólares. Al igual que en el agregado, tales comportamientos difieren con los registrados entre 1993-2002, cuando las exportaciones fabriles a Brasil aumentaron el 9,4\% anual, mientras que las compras de manufacturas brasileras cayeron el 4,1\% anual $^{(3)}$.

- En términos de la significación que asume el intercambio con la Argentina para Brasil, la etapa 2002-2008 también denota algunos cambios importantes. En 2002, las ventas representaban apenas el 3,8\% del total de las exportaciones brasileras, mientras que las importaciones provenientes de la Argentina explicaban el 10,0\% del total. Seis años después tales porcentuales pasaron a ser de 8,9\% y 7,6\%, respectivamente ${ }^{(4)}$.

Hasta aquí casi parece un aquelarre deshilvanado de fenómenos económicos que vinculan a la economía argentina con su "socio" mayor en el ámbito del Mercosur. La

(1) Disponível em: <http://websie.eclac.cl/sisgen> Consultado el: 20.12.2009.

(2) Disponível em: <http/www.indec.gov.ar> Consultado el: 21.12.2009.

(3) Disponível em: <http/www.cep.gov.ar> Consultado el: 21.12.2009.

(4) Disponível em: <http://www.desenvolvimento.gov.br> Consultado el: 18.12.2009. 
incorporación de una nueva variable no hace más que introducir otro componente a ese pandemonium temático: la Inversión Extranjera Directa - IED. Así, el proceso de extranjerización de ambas economías (con intensidades y características diversas y heterogéneas en lo temporal y por sus connotaciones estructurales) y los respectivos grados de inserción empresaria en los países vecinos, introducen interrogantes adicionales.

Desde hace largos años Brasil ha venido constituyendo el principal receptor de IED en América Latina, mientras que la Argentina, con la excepción de los inicios de la década de 1990 (privatizaciones mediante), siempre se ubicó en lugares muy distantes: de acuerdo a información de la CEPAL (2009), en 2008 el flujo de IED a Brasil (45.058 millones de dólares) casi sextuplicó al orientado hacia la Argentina (7.979 millones de dólares). Sin embargo, más allá de esas diferencias de magnitudes, tal vez el fenómeno más interesante de remarcar es que Brasil pasó a constituirse en el segundo país de origen del flujo de IED hacia la Argentina y a consolidarse como el quinto en cuanto al stock acumulado de IED en $2007^{(5)}$. En contraposición, de acuerdo al último censo (2005) de capitales extranjeros que se realiza en Brasil cada cinco años, la participación de inversores argentinos en el stock de inversión extranjera directa es de apenas el $0,4 \%{ }^{(6)}$.

Sin duda, las fenomenologías resaltadas invitan a la reflexión y muy difícilmente pueda encontrarse un único factor causal o desencadenante de todas ellas. No obstante, la experiencia argentina en el marco de la convertibilidad (vigente entre abril de $1991 \mathrm{y}$ enero de 2002), y su no menos traumática ruptura con la consiguiente hiperdevaluación en 2002 y el posterior mantenimiento de un dólar “alto”, asumen un papel más que protagónico en la explicación de tales procesos.

Como un intento de coadyuvar a la explicación de esos escenarios, en la próxima sección se aborda el análisis de la reactivación económica y fabril de la economía argentina en la posconvertibilidad, donde, junto a la implosión del régimen de conversión fija, culminó la hegemonía plena de la especulación valorización financiera como núcleo central de la acumulación y reproducción del capital local; sin que ello haya derivado hasta el momento en la consolidación de un nuevo modelo de acumulación ${ }^{(7)}$.

En la tercera sección, siempre teniendo como eje el desempeño de la industria argentina, se jerarquiza el estudio de dos rasgos estructurales que caracterizan el comportamiento fabril durante la posconvertibilidad y que, con sus matices, se remontan al decenio de 1990: la concentración y extranjerización de la producción manufacturera.

La cuarta sección incorpora algunas respuestas a los interrogantes planteados precedentemente a partir del análisis de la balanza comercial del sector industrial, con especial detenimiento en la dinámica de los intercambios con Brasil.

(5) Disponível em: < http://www.prosperar.gov.ar/admin/uploadfiles/files> Consultado el: 15.12.2009).

(6) Disponível em: < http//www.bacen.gov.br> Consultado el: 22.12.2009.

(7) Dicho concepto remite a la existencia de un determinado "estilo" de acumulación y reproducción del capital sostenible y sustentable, y de un conjunto de actores económicos y políticos que aseguren su continuidad y profundización en el tiempo. Tales los casos del modelo agro-exportador, el de sustitución de importaciones y el "financiero y de ajuste estructural" vigente entre 1976 y 2001. Sobre el tema de la valorización financiera a escala global, consúltese Chesnais (2001). 
Finalmente, las reflexiones finales intentan rescatar las consideraciones analíticas previas, en un escenario donde el dólar "alto” o "competitivo” parece haberse constituido en el adalid de la estrategia oficial hacia el sector.

\section{REACTIVACIÓN INDUSTRIAL Y CONSOLIDACIÓN DEL PATRóN PRODUCTIVO SECTORIAL EN LA POSCONVERTIBILIDAD}

En un franco y nítido contraste con Brasil, entre 1975 y 2008, la economía argentina ha reconocido catorce años de caída del PIB y veinte de crecimiento, con la particularidad que seis de estos últimos son los correspondientes al último sexenio. En idéntico lapso, Brasil sólo vio decaer su PIB en seis años (el último en 1992), con un crecimiento ininterrumpido desde 1993 (claro que con fluctuaciones y vaivenes de variada intensidad). Sin duda, el ejemplo atípico no es el que ofrece Brasil. Es más, en el caso argentino, hay que remontarse al período 1964-1974 para encontrar más de un sexenio de expansión económica e industrial como la verificada entre 2002 y 2008.

Al respecto, el año 2002, en cuyos primeros días se formalizó la salida del régimen de conversión fija con el dólar estadounidense (un peso = un dólar) que había ingresado en su fase terminal ya en la segunda mitad de 1998, reflejó en toda su intensidad la devastadora resultante de la ruptura de un corsé insostenible como fue la convertibilidad ${ }^{(8)}$. Basta repasar algunos indicadores de ese año crítico: una profunda contracción económica (caída superior al $10 \%$ en el PIB total y el industrial); una pronunciada retracción de los salarios reales (superior al 30\%); dramáticos niveles de pobreza e indigencia (en octubre de 2001: 28,0\% y $9,4 \%$, respectivamente; y en mayo de 2002: 41,4\% y 18,0\%, respectivamente); elevadísimas tasas de desocupación y subocupación de la fuerza de trabajo (en octubre de 2001: 18,3\% y 16,3\%, respectivamente; y en mayo 2002: 21,5\% y 18,6\%, respectivamente); un tipo de cambio con el dólar que a mediados de año había acumulado un incremento aproximado del $265 \%$ para luego estabilizarse en torno al $250 \%$.

Esas expresiones críticas no hacían más que reflejar la presencia de un punto de inflexión entre un “antes”, el de la vigencia de la convertibilidad y de la adhesión plena a las recomendaciones del neoliberalismo (apertura comercial y financiera, desregulación, privatización, precarización del mercado de trabajo), y un “después”, en el que sin lograr revertir muchos de los legados del "modelo de los noventa”, la recuperación de la economía y la industria, la reducción de los márgenes de pobreza e indigencia, el crecimiento del empleo, emergen como parte sustantiva de nuevos y distintos escenarios. Si bien es este último período el que interesa analizar, caben unas breves consideraciones sobre ese "antes”, en tanto muy difícilmente pueda interpretarse el "después” si se prescinde de lo acaecido en la década de 1990, como continuidad y profundización de muchas de las políticas implementadas por la dictadura militar de 1976-1983.

(8) El abandono formal de la convertibilidad tuvo lugar a partir de la sanción de la Ley n. 25.561 el 6/1/02. En Azpiazu y Schorr (2010) se analizan las principales modificaciones sobrevenidas en la orientación macroeconómica desde entonces y sus implicancias más salientes sobre la dinámica y la conformación estructural del sector industrial. 
Durante la convertibilidad, en un contexto caracterizado por la instrumentación de múltiples políticas de ajuste estructural, se registraron cambios de trascendencia en la economía argentina en su conjunto, muy particularmente en su sector manufacturero. Como producto de esa reestructuración económico-política, la industria local se vio seriamente afectada y se consolidaron los procesos de desindustrialización (entendido como la pérdida de participación de las manufacturas en el PIB global) y de reconversión regresiva del sector, cuya génesis histórica se remonta en ambos casos a fines del decenio de $1970^{(9)}$.

Así, por ejemplo, entre 1993 y 2001 el PIB total (medido a precios constantes) se incrementó apenas el 11,6\%, mientras que el industrial decayó el 5,8\% (Gráfico 1). De resultas de ello, continuó ahondándose el proceso de desindustrialización (casi tres puntos porcentuales de pérdida de participación en el PIB global) que, como sesgo de largo plazo, remite al quiebre del modelo sustitutivo resultante de la última dictadura militar.

Esa profundización de la desindustrialización en los noventa estuvo directamente relacionada con la convergencia de diversos factores. En primer lugar, las profundas modificaciones en la estructura de precios relativos de la economía, las que tendieron a consolidar un perfil con un claro sesgo "anti-industrial” (los servicios en general, y los públicos privatizados en particular, junto con las actividades financieras y diferentes elaboradoras de bienes no transables constituyeron los segmentos más favorecidos de la etapa). En segundo lugar, en el marco de un proceso de apertura comercial asimétrica agravado por un importante retraso cambiario, se verificó una significativa desintegración de la producción fabril local que se expresó, entre otros aspectos, en la creciente importancia que asumieron las compras en el exterior de insumos y/o productos finales por parte de las empresas industriales, el cierre de numerosas firmas industriales (sobre todo las de menores dimensiones, en su mayoría imposibilitadas de competir con importaciones “subsidiadas” por la propia apreciación cambiaria), o el corrimiento de muchas compañías hacia actividades vinculadas al armado y/o el ensamblado de partes y piezas procedentes del extranjero, sino directamente a la venta de productos finales importados (a partir del aprovechamiento de los propios canales de comercialización).

(9) La “desindustrialización por modernización y profundización industriales" registrada en gran parte de las naciones más desarrolladas y en varias que se encuentran inmersas desde hace años en un proceso de desarrollo, contrasta con la "desindustrialización por crisis y reestructuración regresiva” de la Argentina. En efecto, en el primer caso la reducción del coeficiente de industrialización ha estado estrechamente ligado a la maduración y la modernización fabriles, así como la generación de diversos efectos propulsores por parte del sector manufacturero, lo que ha derivado en fuertes aumentos en la productividad por incorporación de una variada gama de tecnologías y bienes de capital que han generado una caída en los precios relativos de las manufacturas vis-à-vis los de los servicios, la expansión de los llamados servicios para la industria asociada al dinamismo de los sectores fabriles de punta y una creciente participación en los flujos de las mercancías más dinámicas en el comercio mundial. Por el contrario, en la Argentina el prolongado y sostenido proceso de desindustrialización ha estado asociado a la desarticulación productiva y la reestructuración regresiva del aparato fabril iniciadas con la dictadura militar de 19761983, así como a la pobre performance agregada registrada en materia de acumulación de capital en el nivel interno. Sobre el particular, véase Amsden (2004) y Nochteff (2000). 


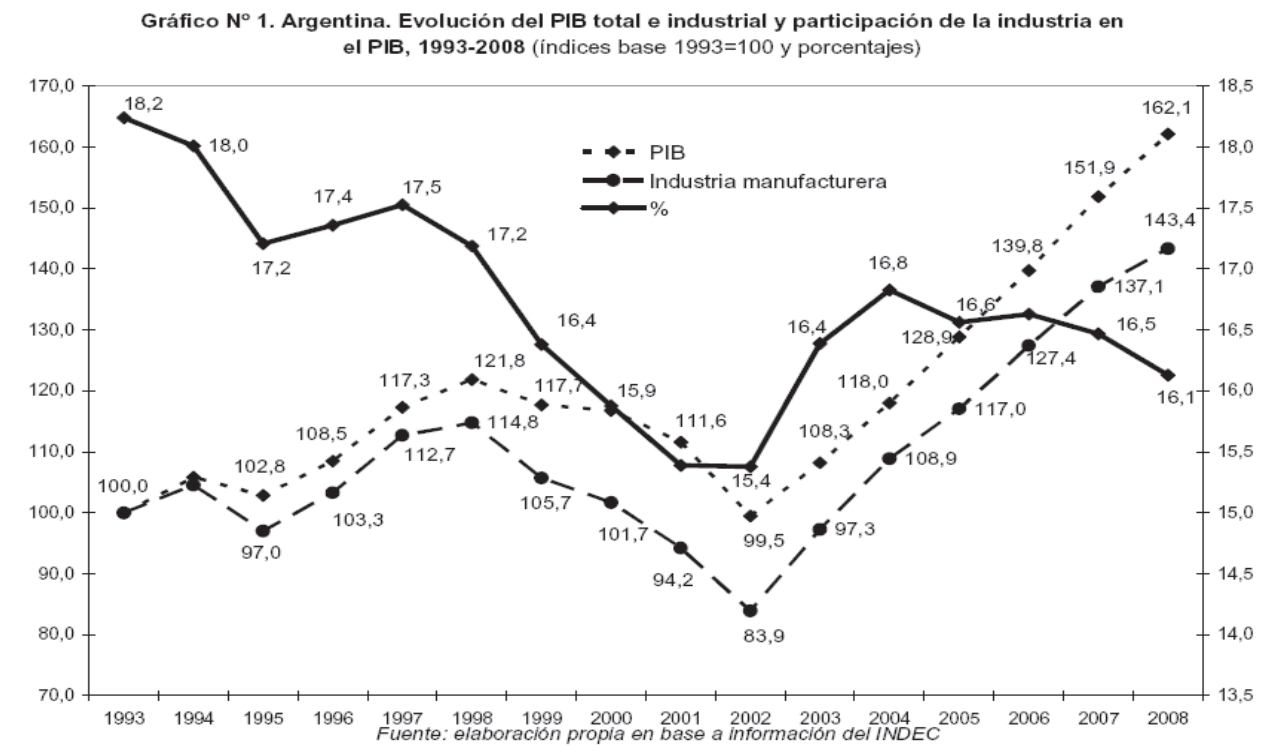

Asimismo, se tendió a consolidar una estructura fabril crecientemente asociada a la explotación de ventajas comparativas naturales (como la producción agroalimenticia y, en menor medida, la refinación de petróleo) e “institucionales” de privilegio (como la automotriz, a favor de un régimen de promoción y protección que terminó por afianzar un perfil fuertemente volcado a tareas de armaduría y ensamblado por parte de las terminales), así como sectores maduros y oligopólicos productores de bienes intermedios de uso difundido (industrias química y siderúrgica).

Por lo menos en términos de desempeño agregado, muy distintos son los escenarios que quedan plasmados a partir de la salida de la convertibilidad, la maxidevaluación y el profundo reordenamiento de la estructura de precios relativos a favor, con sus matices, de los sectores productores de bienes transables (hidrocarburos, minería, agropecuario y gran parte del espectro fabril).

De acuerdo a las evidencias aportadas por el Gráfico 1, a partir de allí y hasta 2008, la economía en general, y la industria manufacturera en especial, han revelado un acelerado y sostenido ritmo de crecimiento que ha permitido atenuar el proceso de desindustrialización de la etapa anterior.

De todas maneras, para evaluar tales logros en su real dimensión, no pueden obviarse ciertas consideraciones. Primero, casi como “efecto rebote”, que recién en el año 2005 se lograron superar, tanto en lo relativo al PIB global como al fabril, los registros correspondientes de 1998, cuando se inició la prolongada fase recesiva que preanunciaba la crisis final de la convertibilidad. Segundo, que a partir de ese mismo año (2005), el crecimiento de la industria se ubica por debajo del agregado (con la consiguiente reducción en el aporte relativo del sector), siendo la construcción (entre los rubros productores de bienes) y el transporte, las telecomunicaciones, el comercio y la intermediación financiera (entre los servicios), los ámbitos de mayor dinamismo durante el último cuatrienio. Es más, en estos últimos años, por su aporte al incremento del PIB total, la industria se vio 
superada por el transporte, las telecomunicaciones y las actividades comerciales. Tercero, si bien el período 2002-2008 emerge como una fase de alto ritmo de crecimiento de la economía y la industria argentinas, el sector manufacturero no parece haberse constituido en el núcleo central de un nuevo modelo de acumulación y, mucho menos, en el vector “ordenador" y articulador de las relaciones económicas y socio-políticas en el país (si bien cumplió un importante papel en la recuperación del nivel de empleo; tema no menor atento a la crítica situación por la que atravesó el país en los años previos).

En ese marco de reactivación fabril, aunque relativamente desacelerada en los últimos años, no se verificaron cambios sustantivos en el perfil productivo sectorial que se fuera consolidando durante la década de 1990. La vigencia de un "dólar alto" sin su correlato en políticas industriales activas devino en el afianzamiento de un patrón de especialización de escaso dinamismo a escala mundial (agroindustrias y commodities), con acotados eslabonamientos virtuosos en términos de empleo y de crecientes estadios en materia de productividad e incorporación de progreso técnico. En su mayoría, se trata de manufacturas que se caracterizan por estructuras de oferta oligopólica, intensivas en capital y en las que, debido en parte a su importante componente exportador, los salarios juegan un rol mucho más asociado a su condición de costo empresario, que de factor dinamizador de la demanda interna (aún cuando muchas agroindustrias también son productoras de bienes salario para el mercado interno). El Cuadro 1 resulta suficientemente ilustrativo.

\section{Cuadro 1 - Estructura de la producción industrial argentina según sector manufacturero, promedio 1993/2001 y 2008 (porcentajes)}

\begin{tabular}{|l|c|c|c|c|}
\hline & \multicolumn{2}{|c|}{$1993-\mathbf{2 0 0 1}$} & \multicolumn{2}{|c|}{2008} \\
\hline & $\mathbf{9}$ & Acum. & \% & Acum. \\
\hline Alimentos y bebidas & 30,5 & 30,5 & 31,1 & 31,1 \\
\hline Sustancias y productos químicos & 11,5 & 42,0 & 11,9 & 43,0 \\
\hline Vehículos automotores, remolques y semirremolques & 7,3 & 49,3 & 8,4 & 51,4 \\
\hline Máquinas y equipos & 4,2 & 53,5 & 5,3 & 56,7 \\
\hline Metales comunes & 4,5 & 58,0 & 5,2 & 61,9 \\
\hline Fabricación de coque y refinación de petróleo & 6,3 & 64,3 & 4,9 & 66,8 \\
\hline Productos de caucho y plástico & 4,1 & 68,4 & 4,4 & 71,2 \\
\hline Edición e impresión & 3,6 & 72,0 & 3,9 & 75,1 \\
\hline Papel y derivados & 3,0 & 75,1 & 3,5 & 78,6 \\
\hline Cuero y derivados & 2,6 & 77,7 & 2,8 & 81,4 \\
\hline Industria metalmecánica (excepto máq. y equip.) & 3,4 & 81,1 & 2,8 & 84,2 \\
\hline Productos minerales no metálicos & 2,6 & 83,7 & 2,7 & 86,9 \\
\hline
\end{tabular}




\begin{tabular}{|l|c|c|c|c|}
\hline & \multicolumn{2}{|c|}{$1993-\mathbf{9 0 1}$} & \multicolumn{2}{c|}{$\mathbf{2 0 0 8}$} \\
\hline & $\mathbf{9}$ & Acum. & $\%$ & Acum. \\
\hline Productos textiles & 3,9 & 87,6 & 2,4 & 89,3 \\
\hline Equipos de radio, TV y comunicaciones & 1,4 & 89,0 & 2,4 & 91,7 \\
\hline Confección de prendas de vestir & 2,9 & 91,9 & 1,9 & 93,6 \\
\hline Madera y productos de madera y corcho & 2,0 & 93,9 & 1,9 & 95,5 \\
\hline Muebles y colchones e industrias ncp* & 2,6 & 95,5 & 1,7 & 97,2 \\
\hline Máq. y aparatos eléctricos & 1,7 & 97,2 & 1,2 & 98,4 \\
\hline Productos de tabaco & 0,7 & 97,9 & 0,6 & 99,0 \\
\hline Instrumentos médicos y de precisión & 0,4 & 98,3 & 0,5 & 99,5 \\
\hline Equipo de transporte & 0,5 & 99,8 & 0,4 & 99,9 \\
\hline Máq. de oficina, contabilidad e informática & 0,2 & 100,0 & 0,1 & 100,0 \\
\hline Total industria & 100,0 & - & 100,0 & - \\
\hline
\end{tabular}

*ncp: no clasificadas en otra parte.

Fuente: elaboración propia en base a datos de la Dirección Nacional de Cuentas Nacionales del Ministerio de Economía y Finanzas Públicas.

Apenas seis ramas industriales dieron cuenta en 2008 de más de las dos terceras partes de la producción fabril, casi todas con participaciones crecientes respecto a las registradas en el período 1993-2001. La industrialización de recursos naturales (esencialmente agropecuarios y derivados de los hidrocarburos), los productos químicos, la siderurgia, la producción de aluminio primario y la "armaduría automotriz" se han consolidado como las actividades centrales del sector industrial argentino a favor, en la generalidad de los casos, de crecientes exportaciones, con bajos salarios a escala internacional y en condiciones externas favorables (sólo morigeradas a partir de la crisis internacional desatada a fines de 2008). El único hecho auspicioso lo brindaría la inclusión de la industria de maquinaria y equipo (5,3\% de la producción fabril en 2008, poco más de un punto porcentual por encima del promedio 1993-2001), fundamentalmente maquinaria agrícola y algunos otros rubros vinculados a las demandas de equipamiento de las ramas que lideran el desempeño sectorial.

De allí se desprende otro tema no menor: por su gravitación, ¿cuáles han sido las ramas que han traccionado la reactivación fabril en la posconvertibilidad o, en otras palabras, las que realizaron una mayor contribución al incremento agregado del PIB fabril? El primer fenómeno a resaltar surge de la evidencia de que apenas diez actividades industriales dieron cuenta de prácticamente el $80 \%$ del incremento registrado en el PIB manufacturero en el período 2002-2008 (Gráfico 2). Al tiempo que, por ejemplo, en el polo opuesto, cuatro actividades no alcanzaron a representar el $3 \%$ del crecimiento del PIB fabril durante el período (todas ellas relevantes en términos de diversificación, eslabonamientos y aporte al 
progreso técnico como electrónica industrial, maquinaria eléctrica, otros equipos de transporte - excluído automotriz —, máquinas de oficina e informática).

El perfil sectorial que ha tendido a consolidarse en la nueva fase expansiva industrial no difiere mayormente del característico de los noventa. Con la salvedad de la fabricación de maquinaria y equipo (donde queda incluída la producción de ciertos equipos utilizados en el sector agrícola y en los propios núcleos de especialización fabril local, como el alimenticio y el siderúrgico), han sido las agroindustrias, la automotriz, el enclave ensamblador de electrónica de consumo en la provincia de Tierra del Fuego ${ }^{(10)}$ y las productoras de commodities e insumos intermedios de uso difundido (acero, aluminio primario, química básica, cemento), las que han realizado una mayor contribución al crecimiento industrial.

\section{Gráfico $N^{\circ}$ 2. Principales ramas fabriles por su aporte al crecimiento del PIB industrial entre} 2002 y 2008 (porcentajes)

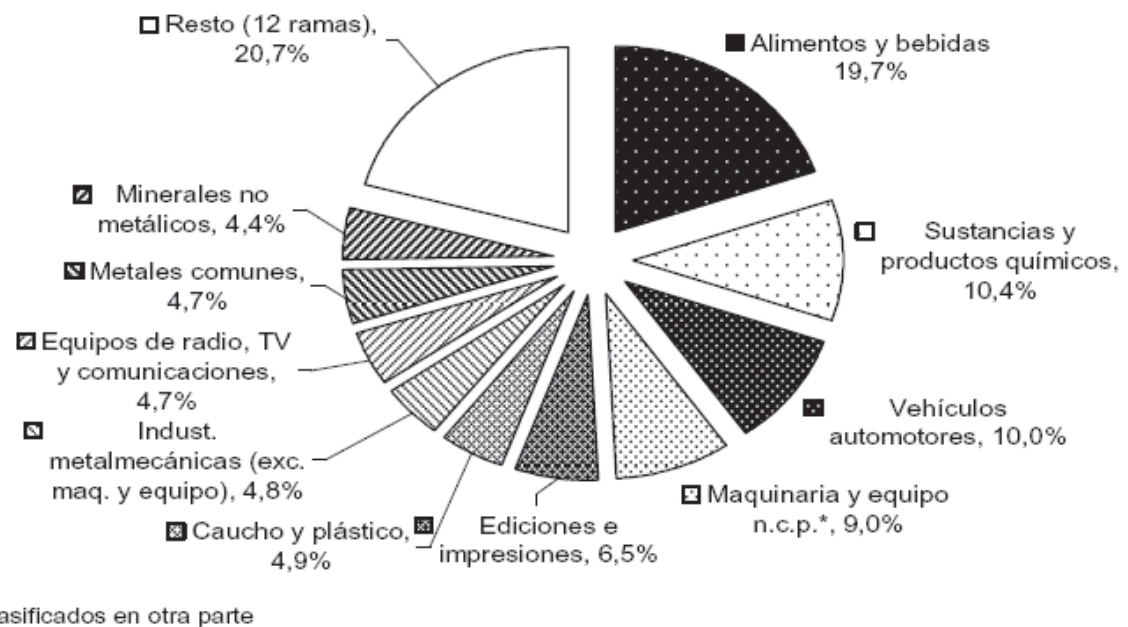

Fuente: elaboración propia en base a información del Ministerio de Economia y Finanzas

En suma, en la posconvertibilidad se ha manifestado un proceso de reindustrialización acotado cuantitativa y cualitativamente, que se ha asociado a la expansión, a ritmos muy disímiles, de casi todas las actividades que integran el entramado manufacturero, con crecientes niveles de inserción en los mercados internacionales. Pero no debería soslayarse el hecho de que teniendo como sustentos básicos al "dólar alto", la baratura relativa de la fuerza de trabajo y la constelación de recursos naturales (dado que casi no hubo políticas activas de fomento a las actividades fabriles), no se verificó un cambio estructural en la industria doméstica, es decir, no se avanzó en la redefinición del perfil de especialización productiva resultante de largos años de políticas neoliberales ni, por ende, en la consolidación de un nuevo modelo de acumulación dominante ${ }^{(11)}$.

(10) Actividad que recientemente fue beneficiada por la extensión de un régimen especial hasta 2023 y la aplicación de "impuestos" especiales a los productos electrónicos que no se fabriquen en dicho territorio.

(11) Sobre esto último, véase Azpiazu y Schorr (2010) y Fernández Bugna y Porta (2007). 


\section{CONTINUIDADES CON LOS AÑOS NOVENTA: CONCENTRACIÓN Y EXTRANJERIZACIÓN}

Con ligeros matices, dos de los rasgos estructurales de la industria argentina consolidados en los noventa se han afianzado en la posconvertibilidad. Se trata de, por un lado, el fenómeno de la concentración económica y, por otro, el de la creciente presencia de empresas transnacionales, por lo menos en el selecto grupo de las 100 empresas industriales más grandes del país (lo que hace presumir, articulado a la mayor gravitación de las mismas en el plano agregado, que involucra al espectro manufacturero en su conjunto).

En cuanto al abordaje del primero de dichos temas, cabe una precisión analítica previa: se considera que el peso relativo de las ventas de las 100 mayores firmas del sector en su relación con el valor bruto de la producción ofrece una excelente referencia ${ }^{(12)}$. Sobre dicha base, el Gráfico 3 brinda una visión acabada del fenómeno de la concentración en la industria, durante la convertibilidad, el crítico año 2002 y la posconvertibilidad.

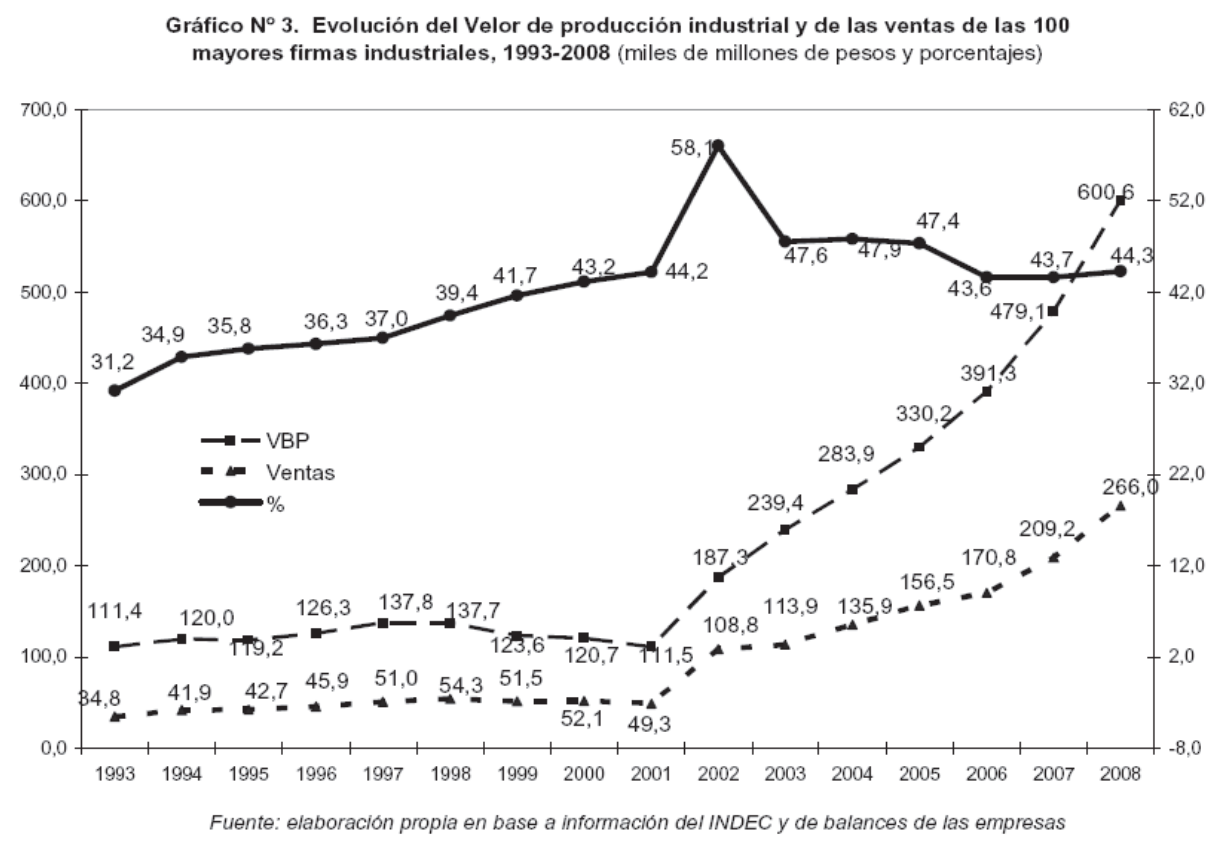

Entre 1993 y 2001, el estancamiento del valor de producción fabril se contrapone con el crecimiento de las ventas de las mayores empresas del sector ( $4,5 \%$ anual acumulativo). De resultas de ello, la participación de las mismas en el conjunto del sector se incrementó en forma sostenida e ininterrumpida, pasando de $31,2 \%$ a 44,2\%. Por su parte, como podía preverse en un contexto de profunda crisis como la registrada en 2002, este último porcentual se elevó en dicho año a 58,1\% (las grandes firmas son, sin duda y por diversas razones, las que mejor pueden “capear el temporal”). A partir de allí, decae el grado de concentración pero ubicándose en un estadio superior al registrado durante la convertibilidad.

(12) Ello no implica desconocer la posible discrepancia entre el valor bruto de producción y las ventas en un año determinado (asociada a la variación de los stocks). Sin embargo, como ha quedado demostrado tales diferencias son mínimas y no alteran para nada los resultados (SCHORR, 2004). 
Un rasgo que emerge como denominador casi común a ambas fases históricas, y que aporta valiosos elementos de juicio a la explicación de ese fenómeno, es el elevado grado de autonomía de esos grandes actores en su relación con el desempeño de la industria en su conjunto. Ello está íntimamente asociado a su marcada y creciente orientación hacia los mercados externos y la atención de la demanda de los sectores de más altos ingresos.

A la vez, ello se conjuga con, entre otros rasgos, su inserción en ramas que se afianzaron en el marco de la reestructuración regresiva del sector de los noventa y se integran a las "ganadoras" en la posconvertibilidad; los privilegios derivados de ciertas acciones y omisiones estatales durante la convertibilidad que no fueron mayormente revertidas en la fase de reactivación fabril (desregulaciones que transfirieron poder regulatorio a quienes ya contaban con el poder de coacción que les otorga el "mercado", la pobre y asimétrica aplicación de la legislación anti-dumping, así como la de defensa de la competencia, etc.); su integración, en muchos casos, en estructuras corporativas de tipo holding con capacidad para desplegar cambiantes estrategias de acumulación y reproducción del capital y de contar con variadas opciones en materia comercial, tecno-productiva, financiera, etc.; y el mantenimiento del privilegiado régimen especial para la industria automotriz (las ocho terminales integran el selecto grupo de la cúpula empresaria manufacturera).

En esa creciente gravitación de la cúpula empresaria fabril subyace, a la vez, otro proceso muy importante: la sostenida extranjerización de la misma y, por ende, de la industria en su conjunto. En su conformación se conjugan, con intensidades diversas en lo temporal, el mayor ritmo de crecimiento de las empresas extranjeras que sus similares de capital nacional (particularmente durante buena parte de la convertibilidad), la radicación de nuevas plantas propiedad de firmas transnacionales y, en el marco de una aceleración de las tendencias a la centralización del capital iniciadas a partir de la última dictadura militar, la adquisición de la totalidad o una porción del capital accionario de grandes firmas nacionales por parte de empresas foráneas.

En términos agregados, y más allá de toda digresión sobre las formas constitutivas del fenómeno de la extranjerización de la industria argentina, el Cuadro 2 aporta valiosa información tanto en lo que se refiere a su intensidad como, en parte, en cuanto a sus formas en lo temporal.

Entre 1993 y 2001 (tendencia en la que también se inscribe el año 1998), las compañías de capital foráneo pasaron de aportar 34 a 56 firmas a la elite industrial, incrementando su participación en las ventas agregadas de 35,3\% a 70,9\%, al tiempo que las nacionales (integradas o no a grupos económicos) perdieron posiciones tanto en términos de cantidad como por su aporte a la producción (22 firmas y 13,6 puntos porcentuales, respectivamente), mientras que las asociaciones de capital sólo lo hicieron, y muy significativamente, en lo relativo a su aporte a las ventas totales de la elite industrial (22,0 puntos porcentuales). En buena medida, ello se ve explicado por dos grandes fenómenos. En primer lugar, la adquisición de YPF (hasta allí, desde su privatización en 1992, una asociación de capitales en la que convergían el Estado nacional, varios provinciales y una multiplicidad de agentes privados) por parte de la española Repsol en 1999. En segundo término, por la disolución, durante esos años, de tres asociaciones que operaban en la industria automotriz (Autolatina, 
Ciadea y Sevel) que conllevó la reasignación de la facturación de las mismas hacia las empresas transnacionales que pasaron a detentar el control de las mismas (Peugeot-Citroën, Volkswagen, Fiat, Ford y Renault) ${ }^{(13)}$.

\section{Cuadro 2 - Argentina. Distribución de las empresas y la participación porcentual en las ventas de la cúpula industrial* según tipo de empresa, 1993, 1998, 2001, 2004 y 2008 (valores absolutos y porcentajes)}

A) CANTIDAD DE EMPRESAS

\begin{tabular}{|c|c|c|c|c|c|}
\hline & $\mathbf{1 9 9 3}$ & $\mathbf{1 9 9 8}$ & $\mathbf{2 0 0 1}$ & $\mathbf{2 0 0 4}$ & $\mathbf{2 0 0 8}$ \\
\hline Nacionales & 54 & 38 & 32 & 31 & 25 \\
\hline Extranjeras & 34 & 54 & 56 & 60 & 72 \\
\hline Asociaciones & 12 & 8 & 12 & 9 & 3 \\
\hline Total & $\mathbf{1 0 0}$ & $\mathbf{1 0 0}$ & $\mathbf{1 0 0}$ & $\mathbf{1 0 0}$ & $\mathbf{1 0 0}$ \\
\hline
\end{tabular}

B) DISTRIBUCIÓN DE LAS VENTAS

\begin{tabular}{|c|c|c|c|c|c|}
\hline & $\mathbf{1 9 9 3}$ & $\mathbf{1 9 9 8}$ & $\mathbf{2 0 0 1}$ & $\mathbf{2 0 0 4}$ & $\mathbf{2 0 0 8}$ \\
\hline Nacionales & 34,4 & 24,9 & 20,8 & 26,9 & 27,8 \\
\hline Extranjeras & 35,3 & 61,6 & 70,9 & 66,9 & 70,4 \\
\hline Asociaciones & 30,3 & 13,5 & 8,3 & 6,2 & 1,8 \\
\hline Total & $\mathbf{1 0 0 , 0}$ & $\mathbf{1 0 0 , 0}$ & $\mathbf{1 0 0 , 0}$ & $\mathbf{1 0 0 , 0}$ & $\mathbf{1 0 0 , 0}$ \\
\hline
\end{tabular}

* La cúpula empresaria está constituida por las 100 firmas industriales de mayor facturación anual. Fuente: elaboración propia en base a información del Área de Economía y Tecnología de la FLACSO.

Por su parte, la disminución en la cantidad de firmas nacionales y en su gravitación en la facturación global de la cúpula estuvo asociada fundamentalmente a que algunos grupos económicos se desprendieron de varias compañías de su propiedad que integraban el panel de las cien de mayor facturación del país, a favor de empresas de capital foráneo (entre otras, Astra, Bagley, Canale e Indupa).

Los cambios registrados en la conformación de la elite industrial entre 2001 y 2008 ilustran diversas fenomenologías. Por un lado, la presencia de las asociaciones pasa a ser marginal, tanto por la cantidad de firmas que aportan (nueve menos, por su desplazamiento a puestos de menor facturación anual o por su adquisición total por parte de capitales

(13) La incorporación de nuevas asociaciones responde a ventas a actores extranjeros de participaciones accionarias en algunas empresas nacionales líderes de menor significación relativa por su facturación anual (Editorial Atlántida, Peñaflor, Trigaglia, Milkaut, Química Estrella). 
extranjeros como en los casos de Editorial Atlántida, Peñaflor, Trigaglia), como por su participación en las ventas agregadas (6,5 puntos porcentuales menos).

En cuanto a las empresas nacionales se verifica un fenómeno atípico: persiste el sistemático decrecimiento de la cantidad de firmas que aportan a la elite (siete menos), pero se incrementa en 7,o puntos porcentuales su participación en la facturación global de las cien líderes. Ello está directamente asociado a la creciente gravitación de algunas empresas controladas por grandes grupos económicos locales con una fuerte presencia exportadora: Aceitera General Deheza, Arcor, Ledesma, Siderca, Siderar, Molinos Río de la Plata, entre otras.

De todas maneras, el fenómeno más relevante es el que se asocia con el hecho de que más del 70\% de las firmas líderes y de la facturación agregada está en manos del capital extranjero. En la posconvertibilidad el papel decisivo lo ha pasado a asumir la adquisición de grandes compañías nacionales, en general oligopólicas en el mercado doméstico y con importante orientación exportadora. En este último escenario ha sido el gran capital brasilero el que desempeñó un papel decisivo contando, en muchos casos, con el apoyo financiero del Banco Nacional de Desenvolvimento Econômico e Social — BNDES a partir de líneas crediticias preferenciales orientadas a la internacionalización de las empresas brasileras.

Varios son los ejemplos significativos: la adquisición por parte de Petrobrás de Pérez Companc Energía (petroquímica y refinerías de petróleo, en lo relativo a presencia industrial); de Cervecería Quilmes por AmBev (luego absorbida por la belga Interbrew); del oligopolio siderúrgico Acindar por parte del grupo brasilero Gerdau, el que con posterioridad pasó a ser controlado por la mega-corporación Arcelor-Mittal ${ }^{(14)}$; el frigorífico Quickfood adquirido por Marfrig que en la Argentina también controla otros frigoríficos con una sólida presencia exportadora (AB\&P, Estancias del Sur y Best Beef); de Swift Armour a manos del grupo brasilero Friboi, que así pasó a constituirse en el principal referente del mercado mundial de carnes ${ }^{(15)}$; y de la líder indiscutida del mercado cementero (Loma Negra) y una gran empresa textil (Alpargatas) por parte del holding Camargo Correa.

Se trata, en todos los casos, de grandes empresas del medio doméstico que por su generalizada condición de oligopolios en un mercado interno reactivado y/o por su inserción exportadora contaban con amplias potencialidades de crecimiento que, aparentemente, el poco "schumpeteriano" empresariado nacional no estaba dispuesto a explorar. Ello contrasta con la actitud de varios actores transnacionales que, a partir de la intensa centralización del capital que se ha verificado en los últimos años, han pasado a constituirse en núcleos centrales del proceso económico argentino y, como tales, cuentan con un significativo poder de veto sobre la orientación del funcionamiento estatal.

En ese sentido, y ante la inexistencia de cambios significativos en el perfil de especialización de la industria local (sección II) y de políticas activas que trasciendan la

(14) En estos dos últimos casos, seguramente los grupos brasileros mejoraron sustantivamente su valorización patrimonial a partir de su presencia oligopólica en la Argentina (BIANCO et al., 2008).

(15) Otro importante frigorífico que, como los anteriores, tiene una significación especial en la distribución de la cuota Hilton es Finexcor, que fue adquirido por Cargill. 
vigencia de un dólar “competitivo” y el bajo costo relativo de la mano de obra en el plano internacional, la creciente gravitación de grandes empresas de capital foráneo, que aún cuando tengan una fuerte orientación exportadora tienden a evidenciar un superior coeficiente importador por unidad de producto que sus similares de capital nacional, constituye un elemento de contexto que invita a preguntarse por los impactos más salientes de la reactivación fabril de la Argentina sobre el intercambio de bienes industriales con el exterior.

\section{REACTIVACIÓN INDUSTRIAL E IMPACTOS SOBRE EL COMERCIO EXTERIOR DE MANUFACTURAS}

La implosión del régimen de convertibilidad y la salida del mismo a partir de una por demás significativa depreciación real de la moneda, con el consiguiente e intenso reordenamiento de la estructura de precios relativos de la economía, debían traer aparejadas mutaciones trascendentes en la balanza comercial agregada y, en particular, en la de bienes industriales. Al respecto, era de esperar un aumento importante de las exportaciones manufactureras a favor de la confluencia de una nueva paridad cambiaria, altos niveles de capacidad ociosa, abaratamiento real de los costos salariales y los insumos locales, así como de los financieros y los servicios. Y también la emergencia de una acelerada sustitución de importaciones ante el encarecimiento de los bienes importados y la propia paulatina recuperación de la demanda interna.

Más aún, si la vigencia del dólar “alto” o "competitivo” y los incrementos de los costos locales se ubicaban por debajo de la devaluación, a juicio de diversos actores sociales quedarían conformadas las condiciones necesarias y suficientes para garantizar una expansión industrial que conllevaría cambios en el patrón de especialización y de inserción internacional de la economía argentina. Al margen, claro está, en esas visiones favorables al nuevo planteo económico, de toda consideración sobre la complementación de ese escenario general con políticas industriales activas y específicas que "sub-dimensionaran" la capacidad autoregulatoria de los “mercados” y promovieran transformaciones sustantivas y virtuosas en la estructura productiva sectorial, que garantizaran una mejora cualitativa en su inserción a escala mundial.

Tales visiones se vieron alentadas originalmente por la rápida reversión del déficit en la balanza comercial de productos fabriles que fuera una constante en los años noventa, sólo morigerado pari passu la profundización del proceso recesivo que se inició en la segunda mitad de 1998, preanunciando la crisis terminal de la convertibilidad. Sin embargo, a pesar del sostenido crecimiento de las exportaciones industriales, el superávit comercial registrado en 2002 (casi diez mil millones de dólares, monto incluso superior al del total de las importaciones en dicho año) decreció ininterrumpidamente hasta devenir en déficit comercial en el bienio 2007-2008 (Gráfico 4).

Ello invita a reflexionar en torno a si alcanza con garantizar un tipo de cambio "alto" y "competitivo" para avanzar en un proceso de reindustrialización y de reconfiguración del entramado fabril local; menos dependiente, autosostenido y con capacidad motriz para 
generar eslabonamientos virtuosos y viabilizar la internalización de desarrollos tecnológicos acordes a las potencialidades locales y el propio escenario internacional.

En la búsqueda de respuestas cabe incorporar una somera descripción del intercambio comercial de productos industriales en la posconvertibilidad pero revisando, a la vez, su comportamiento durante los años noventa. Como se infiere del gráfico de referencia, durante la vigencia del régimen de caja de conversión la industria argentina acumuló considerables déficit comerciales que alcanzaron su nivel máximo en 1998 (11,2 miles de millones de dólares) para después decaer, esencialmente a raíz de los menores requerimientos de importaciones derivados de la propia recesión interna.

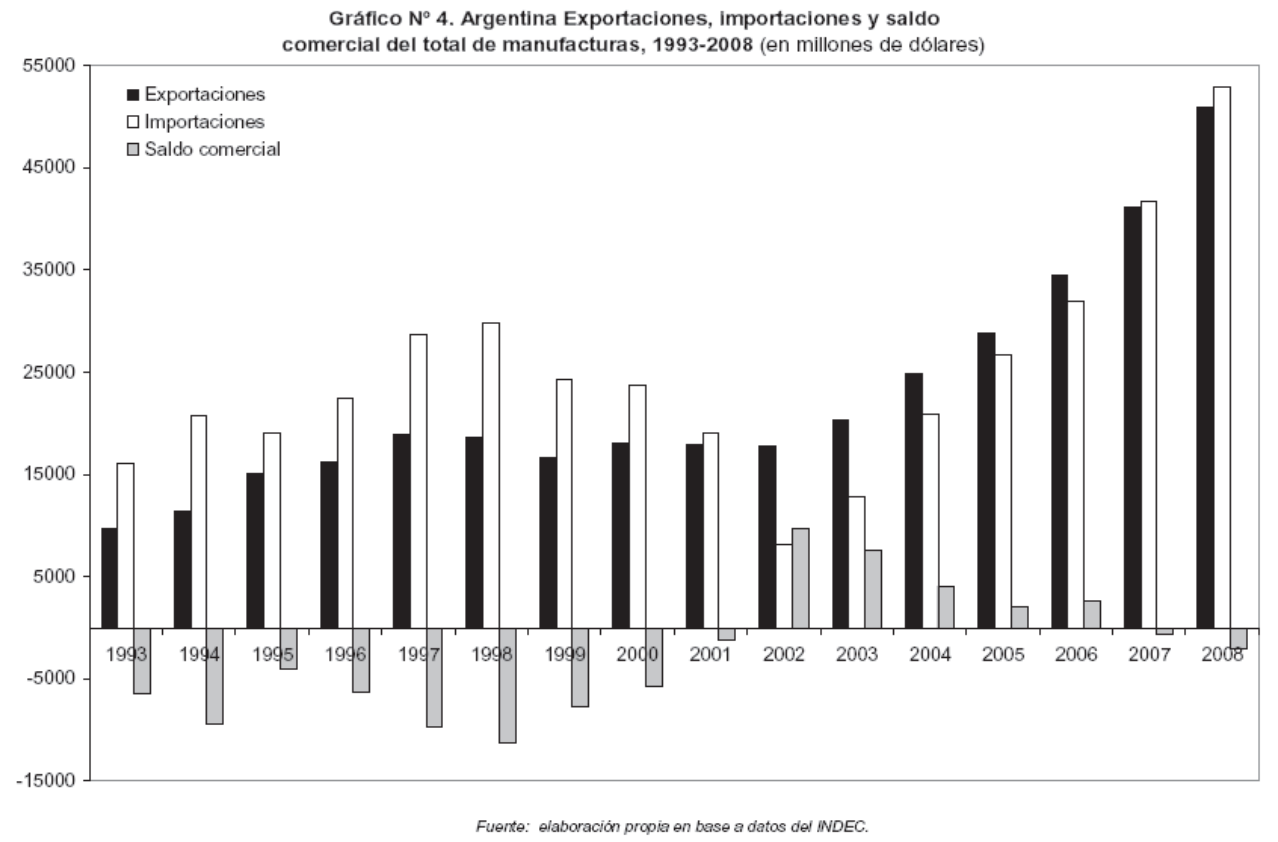

La conjunción de la apertura de la economía (agravada por la escasa o nula recurrencia al control de prácticas de dumping en aras de la "ansiada” estabilidad de los precios internos) y el creciente retraso cambiario, tuvieron el obvio doble efecto de alentar importaciones competitivas de la producción local y el de limitar las posibilidades de exportación, salvo para aquellas asociadas al ciclo económico interno, por su condición de industrias de procesos con alta intensidad de capital y la necesidad de recuperar sus costos fijos. En este último plano, durante la década de 90, se consolidaron ciertos sectores y actores que al margen de las ventajas comparativas estáticas, pero a favor de ciertos contextos operativos privilegiados por las políticas públicas, terminaron por constituirse en importantes plataformas de exportación. Casos ilustrativos los brindan, entre otros, la industria siderúrgica y la producción de aluminio primario y, en un plano relativamente similar, el sector automotor (terminales). Asimismo, a favor de la dotación local de recursos naturales, las agroindustrias y, en menor medida, los derivados del petróleo se conformaron en rubros centrales de las ventas al exterior de mercancías fabricadas en el ámbito manufacturero. 
Por su parte, las abaratadas importaciones industriales (apertura y rezago cambiario mediante) asumieron un papel protagónico en el regresivo redimensionamiento fabril que se verificó por la vía de la sustitución de producción local y/o, como componente decisivo, el usufructo del poder oligopólico de mercado por parte de algunas grandes firmas (Sección II).

Como se señaló, el año 2002 emerge como un punto de quiebre donde la propia intensidad de la crisis interna derivó en una por demás significativa reducción de las importaciones (por debajo de los registros de toda la década de los noventa), al tiempo que los saldos exportables (altos niveles de ociosidad de la capacidad productiva, nueva paridad cambiaria y abaratamiento relativo de los restantes costos domésticos, sobre todo los salarios) imprimieron un cambio radical en la balanza comercial del sector.

Sin embargo, como una evidencia insoslayable de que no basta la vigencia de un dólar "alto" y bajos costos salariales a escala mundial, incluso en un escenario internacional receptivo de los principales rubros del perfil exportador de la Argentina (tanto en cantidades como en precios), en los años subsiguientes persistió el sesgo expansivo de las exportaciones industriales, pero a un ritmo muy por debajo del evidenciado por las compras en el exterior de productos manufacturados: entre 2002 y 2008, las primeras se incrementaron a una tasa media de 18,9\% anual y las importaciones lo hicieron al 38,4\% anual acumulativo (entre esos años se pasó de un superávit del orden de los 9,7 miles de millones de dólares a un déficit de 2,0 miles de millones).

En suma, esas condiciones de contexto (local e internacional), sin cambios estructurales de significación, permitieron mantener una cierta expansión de las ventas al exterior de commodities industriales, pero resultaron más que insuficientes para sustentar un proceso de sustitución de importaciones que, como tal, sentara las bases para revertir largos años de desmantelamiento y reestructuración regresiva de la industria. En otros términos, la inexistencia de políticas activas tendientes a la reconstrucción de encadenamientos productivos, de mayor incorporación de valor agregado, de segmentos de media o alta densidad tecnológica y, por ende, de redefinición del perfil de especialización y las consiguientes formas de inserción en el mercado internacional de la industria argentina, parece emerger como un serio condicionante en el futuro desempeño sectorial.

En ese marco adquiere particular interés analítico la revisión, en idéntico período, del comportamiento del intercambio comercial de bienes industriales con el principal socio del Mercosur de la Argentina: Brasil. Naturalmente, sus resultantes no hacen más que plasmar varias décadas de marcados contrastes en materia de políticas industriales y de dinámica y patrón de desenvolvimiento de los respectivos sectores pero, igualmente, aportan valiosos elementos de juicio en torno a la relación bilateral durante los años noventa y en la posconvertibilidad.

Al respecto, se abordarán tres dimensiones de estudio que, aunque complementarias, permitirán captar y precisar algunos de los rasgos sobresalientes de tal vínculo. Primero, una ligera visión de los datos agregados en cuanto al intercambio comercial de manufacturas entre 1993 y 2008. Segundo, a manera de imagen puntual de los respectivos perfiles del comercio, la identificación de los principales rubros del intercambio en 2008. Tercero, y 
nuevamente desde la dinámica del comercio bilateral en la última década y media, se analizan dos complejos sectoriales que, por un lado, emergen como de los más críticos en materia de déficit comercial agregado de la industria ${ }^{(16)}$ y, por otro, casi paradójicamente, constituyen dos de los cuatro principales sectores exportadores de manufactureras argentinas: el sector automotor y el de productos y sustancias químicas ${ }^{(17)}$.

Tal como se ve reflejado en el Cuadro 3, con la salvedad del crítico año 2002 para la Argentina, el desequilibrio comercial industrial a favor de Brasil es una constante aunque con intensidades diversas. En dicho cuadro, además de los flujos de exportaciones e importaciones se incluye la relación del tipo de cambio bilateral (índice de paridad). Al respecto, podría plantearse como hipótesis que, al margen de las importantes devaluaciones registradas en Brasil a principios de 1999 y en 2002 y, fundamentalmente, por sus connotaciones sobre la economía real y la propia dinámica de la acumulación del capital, la maxi-depreciación del peso en la Argentina en enero de 2002, no parecería quedar de manifiesto una alta elasticidad del flujo de bienes industriales respecto al tipo de cambio real bilateral sino, más bien, tendería a ser más significativa su vinculación con el respectivo desempeño de ambas economías e industrias donde, frente a la relativa estabilidad de bajas, pero sostenidas tasas de crecimiento brasileras, la significativa recuperación de la Argentina incidió fuertemente sobre la dinámica del comercio bilateral de bienes industriales.

\section{Cuadro 3 - Argentina. Intercambio comercial de manufacturas con Brasil e} índice de paridad peso/real, 1993-2008 (millones de dólares y base $1993=100$ )

\begin{tabular}{|c|c|c|c|c|}
\hline & Exportaciones & Importaciones & Saldo & Índice de paridad \\
\hline 1993 & $1.650,9$ & $3.524,5$ & $-1.873,7$ & 100,0 \\
\hline 1994 & $2.158,4$ & $4.318,1$ & $-2.159,7$ & 105,4 \\
\hline 1995 & $3.759,2$ & $4.225,6$ & $-466,3$ & 120,3 \\
\hline 1996 & $4.223,8$ & $5.227,6$ & $-1.003,8$ & 126,5 \\
\hline 1997 & $5.849,1$ & $7.003,5$ & $-1.154,4$ & 124,4 \\
\hline 1998 & $5.952,3$ & $7.222,8$ & $-1.270,5$ & 81,0 \\
\hline 1999 & $3.979,6$ & $5.611,8$ & $-1.632,2$ & 85,8 \\
\hline 2000 & $4.678,2$ & $6.572,9$ & $-1.894,8$ & 73,1 \\
\hline 2001 & $4.478,6$ & $5.283,5$ & $-804,9$ & 157,5 \\
\hline 2002 & $3.390,2$ & $2.517,1$ & 873,1 & \\
\hline
\end{tabular}

(16) Como podía suponerse a la luz de las políticas implementadas desde mediados de los años setenta en desmedro de la industria local de bienes de capital, en 2008 el mayor déficit comercial se registró en el rubro de maquinaria y equipos (casi 5.400 millones de dólares). Si bien el retraso relativo de dicho segmento se remonta al propio proceso sustitutivo (de allí uno de los rasgos del carácter trunco del mismo), durante más de tres décadas se terminó por desmantelar la masa crítica acumulada durante la fase sustitutiva.

(17) En materia de exportaciones industriales de la Argentina se han consolidado, junto con las agroindustrias y los derivados del petróleo, como los rubros de mayor significación económica. 


\begin{tabular}{|c|c|c|c|c|}
\hline & Exportaciones & Importaciones & Saldo & Índice de paridad \\
\hline 2003 & $3.054,0$ & $4.696,5$ & $-1.642,6$ & 148,3 \\
\hline 2004 & $3.984,3$ & $7.855,8$ & $-3.871,6$ & 158,4 \\
\hline 2005 & $5.479,7$ & $10.327,3$ & $-4.847,6$ & 182,4 \\
\hline 2006 & $6.700,1$ & $11.816,1$ & $-5.116,1$ & 199,5 \\
\hline 2007 & $8.788,8$ & $14.708,8$ & $-5.920,0$ & 215,8 \\
\hline 2008 & $9.590,9$ & $17.683,2$ & $-8.092,3$ & 230,8 \\
\hline
\end{tabular}

Fuente: elaboración propia en base a información del CEP (Centro de Estudios para la Producción, Ministerio de la Producción) y del CEI (Centro de Economía Internacional, Ministerio de Relaciones Exteriores, Comercio Internacional y Culto).

En efecto, al margen del atípico año 2002, donde la profunda contracción de la economía argentina conllevó una significativa caída en sus requerimientos de importaciones encarecidas por la propia maxi-devaluación (tanto en el plano agregado como en las provenientes de Brasil, el valor de las mismas se contrajo a menos de la mitad), las tendencias subyacentes en la relación comercial con Brasil no difieren sustancialmente a las evidenciadas en el nivel global durante la vigencia de la convertibilidad, mientras que en la posconvertibilidad, en el marco de la reactivación de la economía y la industria argentinas, se registra un creciente déficit en el intercambio bilateral, a punto tal que, en 2007 y 2008 , esos saldos superan en más de ocho y casi cuatro veces, respectivamente, al correspondiente al comercio total de manufacturas y, por otro lado, el desequilibrio del último año representa casi el $85 \%$ de las ventas a Brasil.

En otros términos, a pesar de la vigencia en la Argentina de un tipo de cambio "alto" y "competitivo" (que facilitó la casi triplicación del flujo de bienes industriales al Brasil), las limitaciones e insuficiencias de la propia estructura fabril local y la inexistencia de coordinadas políticas de desarrollo industrial conllevaron una creciente demanda de importaciones de Brasil $^{(18)}$.

Ello se ve implícitamente reflejado en las disímiles composiciones del flujo comercial bilateral en 2008 (Cuadros 4 y 5). Así, las colocaciones argentinas en Brasil muestran que casi la cuarta parte responde a productos primarios y manufacturas de origen agropecuario y poco más del 13\% a combustibles y lubricantes. Por su parte, en el caso de las manufacturas de origen industrial, se destacan las exportaciones automotrices (como se analizará más adelante, se trata no obstante de una actividad altamente deficitaria en términos bilaterales) y ciertos productos químicos (donde cabe idéntica consideración).

(18) La reciente implementación de restricciones cuantitativas de importación (licencias no automáticas) que involucran a diversos productos industriales sólo puede ser considerada como medidas de coyuntura que, sin duda, no opacan la necesidad de formular y desplegar políticas industriales activas. 


\section{Cuadro 4 - Argentina. Composición de las exportaciones a Brasil, 2008 (millones de dólares y porcentajes)}

\begin{tabular}{|c|c|c|}
\hline & mill. u\$s & $\%$ \\
\hline Productos primarios & 1.910 & 14,3 \\
\hline Cereales & 1.443 & 10,8 \\
\hline Hortalizas y legumbres sin elaborar & 241 & 1,8 \\
\hline Resto & 226 & 1,7 \\
\hline Manufacturas de origen agropecuario & 1.367 & 10,2 \\
\hline Productos de molinería & 429 & 3,2 \\
\hline Preparados de hortalizas, legumbres y frutas & 198 & 1,5 \\
\hline Productos lácteos & 144 & 1,1 \\
\hline Resto & 596 & 4,5 \\
\hline Manufacturas de origen industrial & 8.355 & 62,5 \\
\hline Material de transporte terrestre & 4.383 & 32,8 \\
\hline Productos químicos y conexos & 1.148 & 8,6 \\
\hline Materias plásticas y sus manufacturas & 765 & 5,7 \\
\hline Resto & 2.059 & 15,4 \\
\hline Combustibles y energía & 1.747 & 13,1 \\
\hline Carburantes & 1.356 & 10,1 \\
\hline Resto & 391 & 2,9 \\
\hline TOTAL & 13.378 & 100,0 \\
\hline
\end{tabular}

Fuente: elaboración propia en base a información del INDEC.

Muy distinta es la composición de las compras en Brasil donde, en correspondencia con los respectivos perfiles productivos, y con las señaladas limitaciones estructurales de la economía y la industria argentinas frente a una prolongada y sostenida recuperación, el papel más protagónico lo asumen los bienes intermedios, los de capital y las partes y piezas para esta última industria. De modo que el señalado desequilibrio en el ámbito industrial y la por demás evidenciada insuficiencia del dólar "alto" o "competitivo", como sustento de un sostenido y sustentable proceso de reindustrialización y reconfiguración estructural del entramado fabril, emergen como restricciones insoslayables en, y para, los futuros senderos evolutivos de la economía argentina. 


\section{Cuadro 5 - Argentina. Composición de las importaciones de Brasil, 2008 (millones de dólares y porcentajes)}

\begin{tabular}{|l|c|c|}
\hline & mill. $\mathbf{u} \$ \mathbf{s}$ & $\mathbf{\%}$ \\
\hline Bienes de capital & 3.767 & 21,0 \\
\hline Bienes intermedios & 6.368 & 35,4 \\
\hline Piezas y accesorios p/ bienes de capital & 3.375 & 18,8 \\
\hline Bienes de consumo & 1.616 & 9,0 \\
\hline Vehículos automotores de pasajeros & 2.612 & 14,5 \\
\hline Combustibles, lubricantes y otros & 242 & 1,3 \\
\hline TOTAL & $\mathbf{1 7 . 9 7 9}$ & $\mathbf{1 0 0 , 0}$ \\
\hline
\end{tabular}

Fuente: elaboración propia en base a información del INDEC.

La tercera de las dimensiones de análisis vinculadas con los profundos cambios en el escenario macroeconómico de la Argentina a partir de la implosión del régimen de conversión fija y sus connotaciones en términos de reactivación de la economía y la industria (en ausencia de una política industrial integral), y los flujos comerciales con Brasil remite a una revisión descriptiva sobre dos sectores industriales que reúnen sendas condiciones comunes: ser parte constitutiva de los principales rubros de exportación de la Argentina y, a la vez, de los de mayor contribución al déficit comercial agregado, tanto en términos globales como en relación con Brasil.

Se trata, en el primer caso, del sector automotor, ámbito en el que en la posconvertibilidad se ha mantenido, con ligeros matices, el llamado régimen para el reordenamiento de la industria automotriz y la importación de automotores (Decreto n. 2.677/91), que había venido resultando plenamente funcional al despliegue estratégico de las grandes trasnacionales (terminales) a escala subregional y mundial ${ }^{(19)}$.

Es en ese escenario donde se inscribe, como uno de sus resultantes, el intercambio bilateral con Brasil donde, como queda claramente reflejado en el Cuadro 6, difieren los sesgos prevalecientes en los noventa respecto a los que se fueran asentando durante la posconvertibilidad y la consiguiente reactivación de la economía argentina. Así, por ejemplo, al margen del bienio 1993-1994, en los años de vigencia de la convertibilidad (pero incluyendo al crítico 2002), el sector automotor argentino fue siempre superavitario en su relación con Brasil (e, incluso, en la mayoría de esos años, también con el resto del mundo). Ello está estrechamente asociado al flujo bilateral de automotores en tanto la industria autopartista registró déficit persistentes.

(19) A título ilustrativo, consúltese Vispo (1999) y Arza y López (2008). 


\section{Cuadro 6 - Argentina. Evolución de los saldos del intercambio comercial con Brasil de los subsectores que conforman el complejo automotor, y resto del mundo, 1993-2008 (millones de dólares)}

\begin{tabular}{|c|c|c|c|c|c|}
\hline & \multicolumn{4}{|c|}{ Brasil } & \multirow{2}{*}{$\begin{array}{c}\text { Resto del } \\
\text { mundo }\end{array}$} \\
\hline & $\begin{array}{c}\text { Vehículos } \\
\text { automotores }\end{array}$ & $\begin{array}{c}\text { Carrocerías y } \\
\text { remolques }\end{array}$ & Autopartes & Total & \\
\hline 1993 & $-144,4$ & $-35,3$ & $-179,1$ & $-358,7$ & $-179,6$ \\
\hline 1994 & $-282,7$ & $-61,5$ & $-185,5$ & $-529,7$ & $-344,2$ \\
\hline 1995 & 323,4 & $-44,4$ & $-62,6$ & 216,4 & 153,8 \\
\hline 1996 & 544,5 & $-71,1$ & $-281,2$ & 192,2 & $-89,0$ \\
\hline 1997 & 970,1 & $-62,6$ & $-311,3$ & 596,1 & 284,8 \\
\hline 1998 & 882,0 & $-53,9$ & $-295,2$ & 533,0 & 237,8 \\
\hline 1999 & 268,7 & $-42,4$ & $-121,7$ & 104,6 & $-17,0$ \\
\hline 2000 & 448,8 & $-33,7$ & $-107,8$ & 307,3 & 199,5 \\
\hline 2001 & 763,5 & $-11,7$ & $-46,7$ & 705,0 & 751,7 \\
\hline 2002 & 477,6 & 2,4 & 37,1 & 517,1 & 480,0 \\
\hline 2003 & $-349,6$ & $-4,4$ & 9,2 & $-344,8$ & $-354,0$ \\
\hline 2004 & $-1.160,9$ & $-4,1$ & 11,1 & $-1.153,9$ & $-1.165,0$ \\
\hline 2005 & $-1.572,4$ & $-1,2$ & $-50,0$ & $-1.623,6$ & $-1.573,6$ \\
\hline 2006 & $-1.261,3$ & $-9,7$ & $-302,6$ & $-1.573,7$ & $-1.271,0$ \\
\hline 2007 & $-1.042,7$ & 14,8 & $-367,4$ & $-1.395,3$ & $-1.027,9$ \\
\hline 2008 & $-1.111, \mathrm{O}$ & $-10,0$ & $-574,0$ & $-1.695,0$ & $-1.121,1$ \\
\hline
\end{tabular}

Fuente: elaboración propia en base a información del CEP.

En contraposición, en la posconvertibilidad, en el marco de un dólar "alto" y "competitivo", las importaciones brasileras superan holgadamente a las ventas a dicho país, a tal punto que, entre 2003 y 2008, el desequilibrio del intercambio resulta ser casi igual o superior al que se verifica con el resto del mundo. Al respecto, cabe destacar que en todos los años del período aludido las importaciones de automotores de Brasil representan más del $75 \%$ del total de las compras de vehículos terminados en el exterior y han estado directamente vinculadas al despliegue de transacciones intra-corporativas por parte de las transnacionales con actividad en ambos países.

También la industria autopartista, en consonancia con las estrategias de las transnacionales y las limitaciones e insuficiencias de las políticas públicas, muestra crecientes desequilibrios bilaterales a partir de 2005. De allí que no resulte casual que buena parte de los productores locales (no vinculados comercial o accionariamente a las terminales) se 
hayan visto enfrentados a situaciones críticas $^{(20)}$. Las permisividades del régimen especial sectorial vigente conllevan, en tal sentido, una profundización del alarmante grado de desintegración local de la producción verificado en la década de $90^{(21)}$.

En suma, la industria automotriz que se fuera consolidando en los noventa como una suerte de actividad fabril de ensamblaje, con ínfima incorporación de investigación y tecnología local y cada vez más acotados eslabonamientos internos parecería haber profundizado tales rasgos en un contexto de significativa recuperación de la economía y, paradójicamente, en un escenario de dólar "alto" y "competitivo" que, supuestamente, alentaría las exportaciones, desincentivaría las importaciones y mejoraría el propio perfil productivo nacional.

Consideraciones no muy disímiles pueden hacerse extensivas al sector químico-petroquímico, que emerge como uno de los principales exportadores de commodities industriales del país, pero que también revela un déficit comercial sistemático (con el resto del mundo) y con Brasil (con la excepción del bienio 2001-2002 — Cuadro 7).

Cuadro 7 - Argentina. Evolución de los saldos del intercambio comercial con Brasil de los subsectores que conforman el complejo químico, y resto del mundo, 1993-2008 (millones de dólares)

\begin{tabular}{|c|c|c|c|c|c|}
\hline & \multicolumn{4}{|c|}{ Brasil } & \multirow{2}{*}{$\begin{array}{l}\text { Resto del } \\
\text { mundo }\end{array}$} \\
\hline & 241 & 242 & 243 & Total & \\
\hline 1993 & $-152,1$ & $-60,9$ & 31,8 & $-181,2$ & $-1.326,6$ \\
\hline 1994 & $-221,3$ & $-70,5$ & 29,6 & $-262,1$ & $-1.605,8$ \\
\hline 1995 & $-246,9$ & $-100,7$ & 54,2 & $-293,4$ & $-1.572,0$ \\
\hline 1996 & $-181,8$ & $-95,9$ & 43,8 & $-233,9$ & $-2.218,2$ \\
\hline 1997 & $-305,5$ & $-131,4$ & 38,8 & $-398,2$ & $-2.500,0$ \\
\hline 1998 & $-170,5$ & $-137,0$ & 62,0 & $-245,5$ & $-2.504,9$ \\
\hline 1999 & $-95,8$ & $-102,3$ & 54,4 & $-143,7$ & $-2.289,4$ \\
\hline 2000 & $-75,6$ & $-83,6$ & 74,4 & $-84,8$ & $-2.291,2$ \\
\hline 2001 & 96,7 & $-103,3$ & 65,8 & 59,2 & $-1.842,3$ \\
\hline 2002 & 190,4 & $-17,0$ & 32,8 & 206,2 & $-453,8$ \\
\hline 2003 & $-96,0$ & $-99,7$ & $-7,0$ & $-202,6$ & $-1.258,6$ \\
\hline
\end{tabular}

(20) Véase López y Ramos (2009).

(21) A juicio de la cámara empresaria que agrupa a los autopartistas argentinos: "Se puede inferir que durante el año 2008 se produjo una desmejora en el nivel de integración de los vehículos de fabricación nacional, teniendo en cuenta que su producción creció un 10\% y las importaciones de autopartes se incrementaron un 24\%" (AFAC, 2009, p. 2). 


\begin{tabular}{|c|c|c|c|c|c|}
\hline \multirow{2}{*}{} & \multicolumn{4}{|c|}{ Brasil } & \multirow{2}{*}{$\begin{array}{c}\text { Resto del } \\
\text { mundo }\end{array}$} \\
\cline { 2 - 6 } & $\mathbf{2 4 1}$ & $\mathbf{2 4 2}$ & $\mathbf{2 4 3}$ & Total & $-1.574,8$ \\
\hline 2004 & $-109,1$ & $-103,1$ & 3,3 & $-208,9$ & $-1.704,0$ \\
\hline 2005 & $-175,0$ & $-143,5$ & $-8,7$ & $-327,2$ & $-1.665,9$ \\
\hline 2006 & $-465,4$ & $-123,4$ & $-10,8$ & $-599,7$ & $-2.578,3$ \\
\hline 2007 & $-447,0$ & $-140,8$ & $-25,5$ & $-613,3$ & $-3.440,6$ \\
\hline 2008 & $-39,7$ & $-49,2$ & $-19,9$ & $-108,8$ & \\
\hline
\end{tabular}

241: Fabricación de sustancias químicas básicas, excepto abonos (incluye: gases comprimidos y licuados, curtientes naturales y sintéticos, materias colorantes básicas, plásticos en formas primarias y caucho sintético).

242: Fabricación de productos químicos (incluye: pinturas, barnices, tintas y masillas, productos farmacéuticos, medicinales, botánicos y veterinarios, jabones, detergentes, cosméticos, perfumes y de higiene y tocador).

243: Fabricación de fibras manufacturadas (artificiales y sintéticas).

Fuente: elaboración propia en base a información del CEP.

En este último caso, la situación deficitaria en la relación con Brasil es una constante en la posconvertibilidad y con la excepción de las fibras manufacturadas en 2004, comprende a todos los subsectores. Dicho desequilibrio revela un sesgo creciente durante la vigencia del dólar "alto" y "competitivo" hasta 2007, en tanto en el último año dicho país fue desplazado por EE.UU. como principal país de origen de las importaciones de sustancias químicas básicas, al tiempo que crecieron sustancialmente las exportaciones argentinas de productos químicos sin, por ello, lograr revertir la situación deficitaria en materia de comercio bilateral.

\section{REFLEXIONES FINALES}

En definitiva, puede concluirse que en la posconvertibilidad se asistió a la profundización del crítico perfil de especialización industrial argentino, lo que se manifestó tanto en el análisis del desempeño productivo de las diferentes ramas que conforman el espectro fabril, como en el del desenvolvimiento comercial externo. De allí que el rasgo distintivo sea el de una industria muy volcada al procesamiento de recursos naturales y con un marcado componente trunco en su perfil constitutivo a raíz de la inexistencia o la debilidad estructural de numerosas actividades claves para la integración del sector.

En ese marco, la acelerada extranjerización empresaria que se ha venido verificando casi sin interrupciones desde mediados de la década de 90 (en la que el gran capital brasilero tuvo un rol protagónico, en especial en los años recientes), lejos de haber contribuido a alterar el vector de especialización fabril de la Argentina, contribuyó a afianzar aún más el señalado cuadro sectorial (lo cual es otra expresión de la ausencia de políticas estatales). De modo que en la actualidad las transnacionales que se desenvuelven en el medio local y que dan cuenta de porciones crecientes de la producción, el valor agregado y las exportaciones sectoriales tienen una "doble" inserción en la industria: por un lado, aquellas 
vinculadas con la “vieja” inserción del país en la división internacional del trabajo (producciones estructuradas sobre la base de las ventajas comparativas estáticas, básicamente materias primas y mano de obra barata); por otro, aquellas ligadas a la "nueva" fase de internacionalización del capitalismo (desverticalización de procesos a escala regional y/o mundial, siendo un ejemplo emblemático el que brinda el sector automotor, en el que, en la relación bilateral, Brasil juega un indudable rol dinamizador del complejo en el nivel regional y Argentina ocupa el lugar de "furgón de cola” asociado a una creciente desintegración de la actividad en el marco de estrategias corporativas definidas en otros ámbitos nacionales) ${ }^{(22)}$.

En ese marco, y sin cuestionar sus afirmaciones para Brasil, cabe recuperar para el caso argentino, pero colocándolas en su justo término (es decir, sobredimensionándolas), las afirmaciones de Kupfer, Ferraz y Caravalho (2009, p. 68): "la actividad industrial se veía enredada en un círculo vicioso de especialización regresiva: mayor competitividad de las actividades basadas en recursos naturales; concentración de la composición de la producción y las exportaciones en los productos con más dependencia de las importaciones; pérdida de la densidad en las cadenas productivas; aumento en la brecha de productividad e innovación con respecto al resto de la industria; mayor atractivo de las inversiones en los sectores de recursos naturales; y aumento de la competitividad en esos sectores. Sin quebrar esa circularidad no deseable, es difícil que se supere el desafío competitivo brindado por el nuevo escenario económico mundial”. A la luz de la experiencia argentina, después de largos años de hegemonía plena del neoliberalismo, la propia reactivación industrial evidenciada en la posconvertibilidad pone en evidencia una situación que, más allá de sus semejanzas esenciales con el diagnóstico previo, coloca al país a "años luz" de la propia experiencia del Brasil.

\section{REFERENCIAS BIBLIOGRÁFICAS}

AFAC. Comercio exterior autopartista. 2008. Buenos Aires: 2009.

AMSDEN, Alice. La sustitución de importaciones en las industrias de alta tecnología: Prebisch renace en Asia. Revista de la CEPAL. Santiago de Chile, n. 82, 2004.

ARCEO, Enrique. América Latina. Los límites de un crecimiento exportador sin cambio estructural. En: ARCEO, Enrique; BASUALDO, Eduardo (comp.). Los condicionantes de la crisis en América Latina. Inserción internacional y modalidades de acumulación. Buenos Aires: CLACSO, 2009.

ARZA, Valeria; LÓPEZ, Andrés. Capitulo 3. El caso argentino. En: LÓPEZ, Andrés y otros. La industria automotriz en el Mercosur. Montevideo, Serie Red MERCOSUR, n. 10, 2008.

AZPIAZU, Daniel; SCHORR, Martín. Hecho en Argentina. Industria y economía, 1976-2007. Buenos Aires: Siglo Veintiuno, 2010.

BIANCO, Carlos; MOLDOVAN, Pablo; PORTA, Fernando. La internacionalización de las empresas brasileñas en Argentina. Buenos Aries: CEPAL, 2008. mimeo.

(22) Sobre las “viejas" y las "nuevas” formas de inserción de la Argentina en el mercado mundial y, más ampliamente, los países periféricos se recomienda consultar Arceo (2009). 
BUGNA, Cecilia Fernández; PORTA, Fernando. El crecimiento reciente de la industria argentina. Nuevo régimen sin cambio estructural. En: KOSACOFF, Bernardo (comp.). Crisis, recuperación y nuevos dilemas. La economía argentina 2002-2007. Buenos Aires: CEPAL, 2007.

CEPAL. La inversión extranjera directa en América Latina y el Caribe 2008. Santiago de Chile, 2009.

CHESNAIS, François (comp.). La mundialización financiera. Génesis, costos y desafíos. Buenos Aires: Losada, 2001.

KUPFER, David; FERRAZ, João Carlos; CARAVALHO, Laura. 50 años en 50. El largo y sinuoso camino del desarrollo industrial en Brasil. Boletín Techint, Buenos Aires, n. 330, 2009.

LÓPEZ, Andrés; RAMOS, Daniela. Inversión extranjeras directa y cadenas de valor en la industria y servicios. En: KOSACOFF, Bernardo; MERCADO, Ruben (eds.). La Argentina ante la nueva internacionalización de la producción. Crisis y oportunidades. Buenos Aires: CEPAL, 2009.

NOCHTEFF, Hugo. ¿Del industrialismo al posindustrialismo? Las desigualdades entre economías. Observaciones preliminares. Realidad Económica, Buenos Aires, n. 172, 2000.

SCHORR, Martín. Industria y nación. Buenos Aires: Edhasa, 2004.

VISPO, Adolfo. Reservas de mercado, cuasi rentas de privilegio y deficiencias regulatorias: el régimen automotriz argentino. En: AZPIAZU, Daniel (comp.). La desregulación de los mercados. Paradigmas e inequidades de las políticas del neoliberalismo. Buenos Aires: FLACSO, 1999. 